\title{
QUANTUM CHEMICAL STUDY ON THE MECHANISM OF THE ADDITION REACTION BETWEEN GERMYLENE AND EPOXYETHANE
}

\author{
XIAOJUN TAN ${ }^{*, a}$, PING LI ${ }^{b}$, WEIHUA WANG ${ }^{b}$, XIULI YANG ${ }^{c}$, GENGXIU ZHENG ${ }^{c}$ \\ ( ${ }^{a}$ College of Medical and Life Science, University of Jinan, Jinan, Shandong, 250022, People's Republic of China) \\ ('Department of Chemistry, Qufu Normal University, Qufu, Shandong, 273165, People's Republic of China) \\ ('College of Chemistry and Chemical Engineering, University of Jinan, Jinan, Shandong, 250022, People's Republic of China)
}

(Received: April 27, 2009 - Accepted: September 9, 2009)

\begin{abstract}
The mechanism of addition reaction between germylene and epoxyethane has been investigated with B3LYP/6-311+G* method, geometry optimization, vibrational analysis and energy property for the involved stationary points on the potential energy surface have been calculated. From the surface energy profile, it can be predicted that there are two reaction mechanisms (1) and (2). The first one (1) is germylene attacks the $\mathrm{O}$ atom of epoxyethane to form a complex 1 (Com1), which is a barrier-free exothermic reaction. Then, Com1 can isomerize to IM1 via a transition state 1a (TS1a), where the potential barrier is $123.7 \mathrm{~kJ} / \mathrm{mol}$. Subsequently, IM1 isomerizes to a product Pro1 via TS1b with a potential barrier of $58.5 \mathrm{~kJ} / \mathrm{mol}$. The other one (2) is germylene attacks the C atom of epoxyethane firstly to form IM2 via a transition state $2 \mathrm{a}$ (TS2a), the potential barrier is $171.0 \mathrm{~kJ} / \mathrm{mol}$. Then IM2 isomerizes to a product Pro2 via TS2b with a potential barrier of $78.8 \mathrm{~kJ} / \mathrm{mol}$. Correspondingly, the reaction energy for the reaction (1) and (2) is -209.0 and $-82.9 \mathrm{~kJ} / \mathrm{mol}$, respectively. Additionally, the orbital interactions are also discussed for the leading complex.
\end{abstract}

Keywords: Germylene, Epoxyethane, Addition reaction, Density functional theory (DFT)

\section{INTRODUCTION}

Germylene is an important active intermediate in some organic germanium reactions. Some special reactions involving germylene, such as insertion reactions $s^{1-4}$, addition reactions ${ }^{5}$, polymerization reactions ${ }^{6}$, and so on, have been regarded as effective methods to synthesize relevant germanium compounds containing new bonds and heterocycles ${ }^{7-9}$. Moreover, the reactions of germylenes are of interest both because of their involvement in the breakdown mechanism of germanes leading to solid germanium (chemical vapor deposition) $)^{10,11}$ and also because of their involvement in germane and organogermane decompositions ${ }^{12}$. Several stable germylenes compounds have been synthesized ${ }^{13-15}$. The first direct kinetic measurements of germylene, $\mathrm{GeH}_{2}$, have been reported by Becerra et al. ${ }^{16}$ using the technique of laser flash photolysis combined with time-resolved laser resonant absorption. Taking the similar technology, more germylenes and their reactions have been studied in detail ${ }^{17-20}$. As to the theoretical study of germylenes, some groups have reported the reaction of germylenes with small molecules, such as ethylene ${ }^{21}$, quinine ${ }^{22}$, oxirane and thiiran ${ }^{23}$. It's reported that many organic germanium compounds have been found to have biologic activity ${ }^{24-26}$. However, the reaction between germylene and strained small-ring compounds, such as epoxyethane, has not been reported so far to our best knowledge. As a representative small-ring molecule, epoxyethane also plays an important role in organic and medical chemistry. Therefore, it is very important to study the addition reaction between germylene and epoxyethane. In the present study, we have systematically investigated the addition reaction between germylene and epoxyethane employing the B3LYP/6-311+G* level of theory. Intermediates (IM), complex (Com), transition states (TS) and products (Pro) have been located on the potential energy surface. The possible reaction mechanisms have been proposed. Hopefully, the present results would be helpful for further experimental and theoretical studies on the similar addition reactions associated with germylene.

\section{Calculation Method}

The density functional theory (DFT ${ }^{27,28}$ ) B3LYP (Becke's three-parameter hybrid function with the non-local correlation of Lee-Yang-Parr ${ }^{29}$ ) method combined with $6-311+\mathrm{G}^{*}$ basis set are employed to locate all the stationary points along the reaction pathways. Frequency analyses have also been carried out to confirm the nature of the minima and transition states. Moreover, intrinsic reaction coordinate (IRC) calculations $\mathrm{s}^{30,31}$ have also been performed to further validate the calculated transition states connecting reactants and products. Additionally, relevant energy quantities, such as reaction energy and energy barriers, have been computed including zero-point vibrational energy (ZPVE) corrections.

Population analysis has been performed employing the natural bond orbital (NBO) method $^{32}$.

All the calculations have been performed using Gaussian 98 programs $^{33}$.

\section{RESULTS AND DISCUSSION}

There are two possible pathways for the addition reaction between germylene and epoxyethane as follows:

$\mathrm{H}_{2} \mathrm{Ge}:+$ epoxyethane $\rightarrow \mathrm{Com} 1 \rightarrow \mathrm{TS} 1 \mathrm{a} \rightarrow \mathrm{IM} 1 \rightarrow \mathrm{TS} 1 \mathrm{~b} \rightarrow$ Pro 1

$\mathrm{H}_{2}$ Ge: + epoxyethane $\rightarrow$ TS2a $\rightarrow$ IM2 $\rightarrow$ TS $2 \mathrm{~b} \rightarrow$ Pro2

Here, reaction (1) is germylene attacks $\mathrm{O}$ atom of epoxyethane to form a complex 1 (Com1), which is a barrier-free exothermic reaction. Com1 then isomerizes to IM1 via a transition state 1a (TS1a). Subsequently, IM1 isomerizes to a product Prol via TS1b. Reaction (2) is germylene attacks C atom of epoxyethane firstly to form IM2 via TS2a, and then IM2 isomerizes to a product Pro2 via TS2b.

Reaction (1) between Germylene and Epoxyethane

The selected geometrical parameters for the complex (Com1), intermediate (IM1), transition states (TS1a, TS1b), and product (Pro1) in reaction (1) are given in Figure 1. Correspondingly, relevant energy quantities have been summarized in Table 1. Figure 2 illustrates the potential energy profile of reaction based on Table 1. As displayed in Figure 2, reaction (1) consists of three steps: the first one is a barrier-free exothermic reaction of $45.1 \mathrm{~kJ} /$ mol, resulting in a complex Com1; the second one is Com1 isomerizes to intermediate IM1 via TS1a with a barrier of $123.7 \mathrm{~kJ} / \mathrm{mol}$. Subsequently, IM1 isomerizes to product Pro1 via TS1b with $58.5 \mathrm{~kJ} / \mathrm{mol}$.
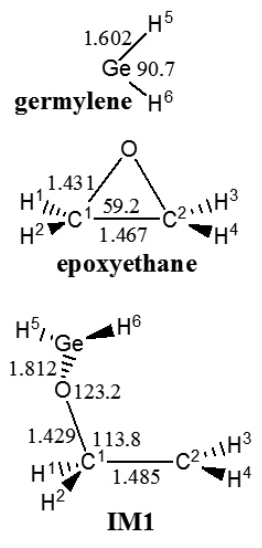

$\square \mathrm{GeOC}^{1} \mathrm{C}^{2}=65.5$

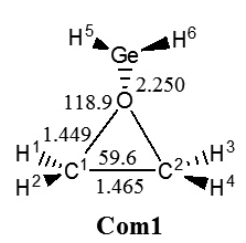

$\square \mathrm{GeOC}^{1} \mathrm{C}^{2}=108.9$

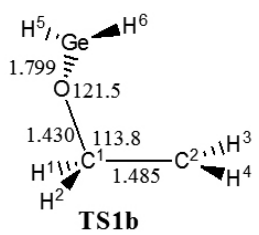

$\square \mathrm{GeOC}^{1} \mathrm{C}^{2}=64.5$

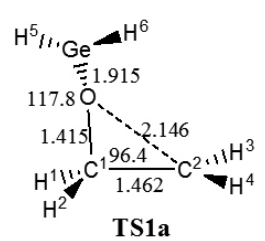

$\square \mathrm{GeOC}^{1} \mathrm{C}^{2}=95.5$

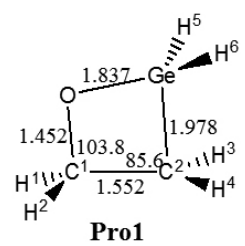

$\square \mathrm{GeOC}^{1} \mathrm{C}^{2}=0$
Figure 1. Optimized structures of reactants, complex (Com), intermediate (IM), transition states (TS), and product (Pro) of reaction (1) at the B3LYP/6$311+\mathrm{G}^{*}$ level of theory, where the bond length and bond angle are in angstrom and degree, respectively. 
Table 1. The electronic structure energies $\left(\mathrm{E}_{\mathrm{SE}}\right)$, zero-point vibrational energies $\left(E_{Z P}\right)$, total energies $\left(E_{T}\right)$ and relative energies $\left(E_{R}\right)$ for the species of the addition reaction between germylene and epoxyethane at the B3LYP/6$311+\mathrm{G}^{*}$ level of theory.

\begin{tabular}{|c|c|c|c|c|}
\hline Spices & $E_{\mathrm{SE}} /$ a.u. & $E_{\mathrm{ZP}} /$ a.u. & $E_{\mathrm{T}}$ a/a.u. & $\begin{array}{c}E_{\mathrm{R}} / \\
(\mathrm{kJ} / \\
\mathrm{mol})\end{array}$ \\
\hline $\begin{array}{c}\mathrm{H}_{2} \mathrm{Ge}:+ \\
\text { epoxyethane }\end{array}$ & -2231.9869915 & 0.067964 & -2231.919027 & 0.0 \\
\hline Com1 & -2232.0083631 & 0.072163 & -2231.936201 & -45.1 \\
\hline TS1a & -2231.9586201 & 0.069517 & -2231.889103 & 78.6 \\
\hline IM1 & -2231.9915229 & 0.068877 & -2231.922646 & -9.5 \\
\hline TS1b & -2231.9681934 & 0.067841 & -2231.900352 & 49.0 \\
\hline Pro1 & -2232.072669 & 0.074024 & -2231.998645 & -209.0 \\
\hline TS2a & -2231.9226431 & 0.068749 & -2231.853894 & 171.0 \\
\hline IM2 & -2231.9755386 & 0.069148 & -2231.906390 & 33.2 \\
\hline TS2b & -2231.9439178 & 0.067159 & -2231.876759 & 112.0 \\
\hline Pro2 & -2232.0233744 & 0.072772 & -2231.950603 & -82.9 \\
\hline
\end{tabular}

${ }^{\mathrm{a}} E_{\mathrm{T}}=E_{\mathrm{SE}}+E_{\mathrm{ZP}}$

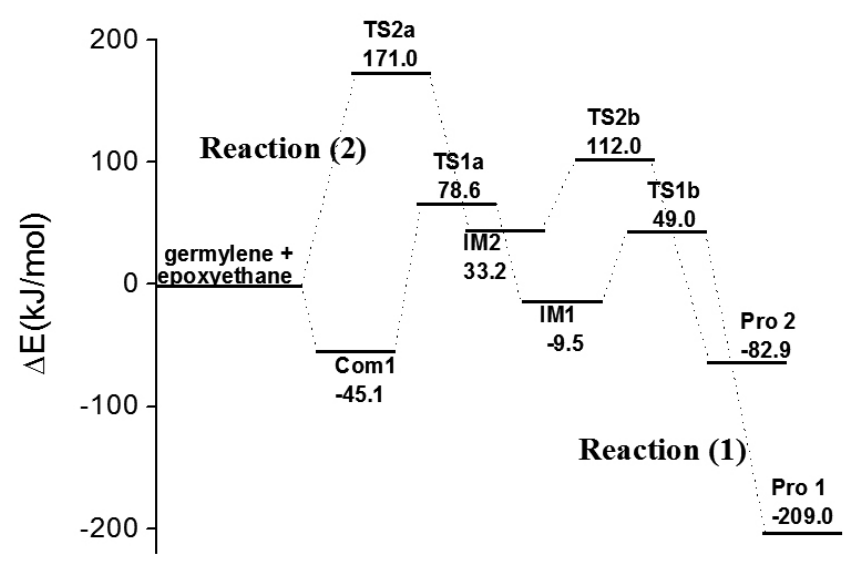

Figure 2. Potential energy surface for the addition reaction between germylene and epoxyethane at the B3LYP/6-311+G* level of theory.

When germylene approaches the $\mathrm{O}$ atom of epoxyethane, it can form a complex (Com1) with epoxyethane, which is a barrier-free process. In Com1, the conformation of epoxyethane changes slightly compared with that in isolated epoxyethane. For example, the bond length of $\mathrm{C}^{1}-\mathrm{C}^{2}$ in $\mathrm{Com} 1$ and isolated epoxyethane is almost equal to each other. At the same time, the bond length of $\mathrm{O}-\mathrm{C}^{1}$ has been prolonged slightly by $0.018 \AA$, denoting the weakening of the $\mathrm{O}-\mathrm{C}^{1}$ bond. On the basis of the population analyses, some electrons on $\mathrm{O}$ atom have been transferred to Ge atom, where the NBO charges on $\mathrm{O}$ and $\mathrm{Ge}$ are $-0.548(-0.547)$ and $0.526(0.318)$ for reactants (Com1), respectively. To investigate this combined process of germylene and epoxyethane, the potential energy curve for the Com1 has been constructed along the distance between two fragments. As displayed in Figure 3, the energy of the system decreases continuously before combination. Actually, no transition state has been located for this combined process to our best ability.

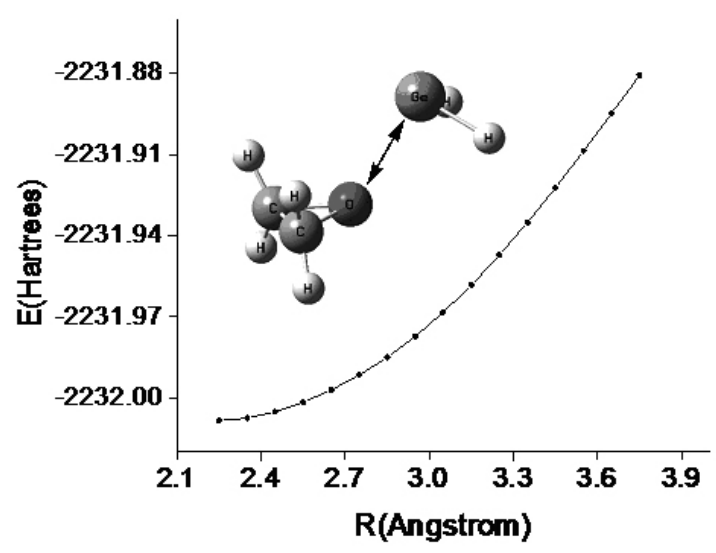

Figure 3. Energy changes in the combined process of Com1 along with the distance between two fragments at the B3LYP/6-311+G* level of theory.

As illustrated in Figure 4, the formation mechanism of Com1 can be explained by the frontier molecular orbital (MO) analysis. The unoccupied $p$ orbital (main component of LUMO) of the Ge of germylene overlaps with the $p$ electron at the $\mathrm{O}$ of epoxyethane, consequently forming $p \rightarrow p$ of $\mathrm{O}-\mathrm{Ge}$ donoracceptor bond, which changed the two reactants into the Com1.

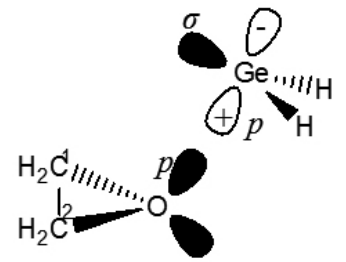

Figure 4. Frontier molecular orbital (MO) symmetry-adaption of germylene and epoxyethane.

The unique imaginary frequency of the transition state TS1a is $341.815 \mathrm{i}$ $\mathrm{cm}^{-1}$, and the transition state can therefore be affirmed as real. According to the calculation of the IRC of TS1a and further optimization for the primary IRC results, TS1a connects Com1 and IM1. In TS1a, the distance of O-C $\mathrm{C}^{1}$ and $\mathrm{O}-\mathrm{C}^{2}$ is 1.415 and $2.146 \AA$, respectively. Compared with the Com1, the distance of $\mathrm{O}-\mathrm{C}^{2}$ in TS1a is elongated by $0.697 \AA$, which denotes the bond of $\mathrm{O}-\mathrm{C}^{2}$ to be ruptured and three-membered epoxyethane ring to be spoiled. At the same time, the angle of $\mathrm{OC}^{1} \mathrm{C}^{2}$ in TS1a changed to $96.4^{\circ}$, which can decrease the angle tensility of $\mathrm{OC}^{1} \mathrm{C}^{2}$. Furthermore, the distance between $\mathrm{Ge}$ and $\mathrm{O}$ is 1.915 $\AA$, which is shortened by $0.335 \AA$ compared with the corresponding distance in the Com1, suggesting that the new $\mathrm{Ge}-\mathrm{O}$ bond is starting to be formed.

In intermediate IM1, the distance between $\mathrm{O}^{-} \mathrm{C}^{1}$ is $1.429 \AA$, which is the normal length of $\mathrm{O}-\mathrm{C}$ single bond approximately. The distance between $\mathrm{Ge}$ and $\mathrm{O}$ decreased to $1.812 \AA$, which is shortened by $0.103 \AA$ compared with the corresponding distance in the TS1a, suggesting the formation of the new Ge-O bond. At the same time, because of the release of the restriction of small ring, the bond length of $\mathrm{C}^{1}-\mathrm{C}^{2}$ is elongated to $1.485 \AA$, which is elongated by 0.020 $\AA$ compared with the corresponding distance in the Com1. The angle of $\mathrm{OC}^{1} \mathrm{C}^{2}$ is $113.8^{\circ}$, denoting that the $\mathrm{C}^{1}$ atom adopts the normal $s p^{3}$ hybridization state. There is an unconjugated electron in $\mathrm{C}^{2}$ and Ge, respectively. The dihedral angle of $\mathrm{H}^{3} \mathrm{C}^{2} \mathrm{C}^{1} \mathrm{H}^{4}$ is $170.1^{\circ}$. As a contrast, the dihedral angle of $\mathrm{H}^{1} \mathrm{C}^{1} \mathrm{C}^{2} \mathrm{H}^{2}$ and $\mathrm{H}^{5} \mathrm{GeOH}^{6}$ is only $117.2^{\circ}$ and $117.5^{\circ}$, respectively. Therefore, $\mathrm{C}^{2}$ adopts $s p^{2}$ hybridization state. Since $\mathrm{C}^{2}$ and Ge have unconjugated electron, IM1 has higher energy, which can transfer to more stable conformer Pro1.

The unique imaginary frequency of the transition state TS1b is $932.741 \mathrm{i}$ $\mathrm{cm}^{-1}$, and TS1b connects IM1 and Pro1. In TS1b, the angle of $\mathrm{OC}^{1} \mathrm{C}^{2}$ is $121.5^{\circ}$, which is reduced compared with the corresponding angle in the IM1 $\left(123.2^{\circ}\right)$. At the same time, the dihedral angle of $\mathrm{GeOC}^{1} \mathrm{C}^{2}$ is $64.5^{\circ}$, which is decreased compared with the corresponding dihedral angle in the IM1 $\left(65.5^{\circ}\right)$, suggesting the planar structure Prol is to be formed.

Pro1 has a planar structure. Two carbon atoms and the germanium atom adopt $s p^{3}$ hybridization and the bond lengths of $\mathrm{C}-\mathrm{C}$ and $\mathrm{C}-\mathrm{O}$ are 1.552 and $1.452 \AA$, respectively. The angle tensility in four-membered ring is smaller 
than that in three-membered ring. Therefore the Pro1 is more stable than IM1. Based on the present calculations, the energy of Pro1 is lower by $199.5 \mathrm{~kJ} / \mathrm{mol}$ than IM1.

\section{Reaction (2) between Germylene and Epoxyethane}

When germylene approaches the carbon atom of epoxyethane, it can form an intermediate (IM2) with epoxyethane via a transition state TS2a, then IM2 isomerizes to Pro2 via TS2b. The geometrical parameters for the intermediate (IM2), transition states (TS2a, TS2b), and product (Pro2) in reaction (2) are given in Figure 5. Correspondingly, relevant energy quantities have been summarized in Table 1. Figure 2 illustrates the potential energy profile of reaction (2) based on Table 1. As displayed in Figure 2, it can be directly seen that reaction (2) consists of two steps: the first one is the formation of IM2 between germylene and epoxyethane via TS2a, the potential barriers is 171.0 $\mathrm{kJ} / \mathrm{mol}$; then, IM2 isomerizes to product Pro2 via TS2b with a barrier of 78.8 $\mathrm{kJ} / \mathrm{mol}$.
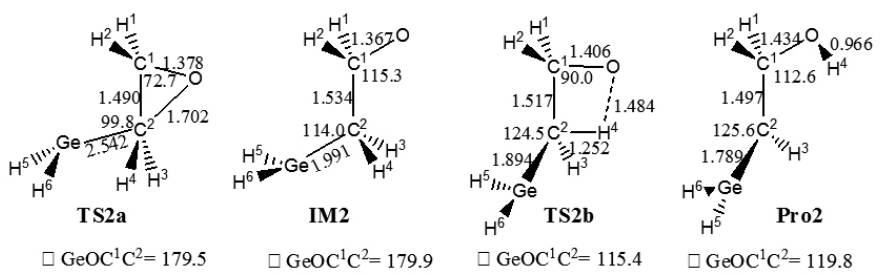

Figure 5. Optimized structures of intermediates (IM), transition states (TS), and products (Pro) of reaction (2) at the B3LYP/6-311+G* level of theory, where the bond length and bond angle are in angstrom and degree, respectively.

The unique imaginary frequency of the transition state TS2a is $754.897 \mathrm{i}$ $\mathrm{cm}^{-1}$, and the transition state can therefore be affirmed as real. According to the calculation of the IRC of TS2a, and further optimization for the primary IRC results, TS2a connects reactants and IM2. In TS2a, the angle of $\mathrm{OC}^{1} \mathrm{C}^{2}$ is $72.7^{\circ}$, which is increased compared with the corresponding angle in the isolated epoxyethane $\left(59.2^{\circ}\right)$. At the same time, the bond length of $\mathrm{C}^{1}-\mathrm{C}^{2}$ increased by $0.023 \AA$ compared with that in the isolated epoxyethane, suggesting the three-membered structure of epoxyethane is to be unfolded. Additionally, the distance of $\mathrm{C}^{2}-\mathrm{Ge}$ reach to $2.542 \AA$, which denotes the bond of $\mathrm{C}^{2}-\mathrm{Ge}$ is to be formed.

In IM2, both the $\mathrm{C}^{1}$ and $\mathrm{C}^{2}$ adopt $s p^{3}$ hybridized state. The angle of $\mathrm{OC}^{1} \mathrm{C}^{2}$ is $114.0^{\circ}$, which denotes that the three-membered ring of epoxyethane is unfolded. At the same time, there is an unconjugated electron in $\mathrm{O}$ and $\mathrm{Ge}$, respectively. Therefore, IM2 has higher energy and it can transfer to more stable conformer Pro2.

The unique imaginary frequency of the transition state TS2b is $1197.6 \mathrm{~cm}$ ${ }^{1}$, and TS2b connects IM2 and Pro2. In TS2b, the distance of $\mathrm{C}^{2}$-Ge has been shortened to $1.894 \AA$, denoting the $\mathrm{C}^{2}$-Ge to be formed. The distance of $\mathrm{C}^{2}-\mathrm{H}^{4}$ is about $1.252 \AA$, which is prolonged by $0.159 \AA$ compared with that in IM2. At the same time, the distance of O- $\mathrm{H}^{4}$ reaches to $1.484 \AA$, which is shortened largely compared with that in IM2. Thus, in the TS2b, the new $\mathrm{O}-\mathrm{H}^{4}$ bond is to be formed and the $\mathrm{C}^{2}-\mathrm{H}^{4}$ bond is to be broken simultaneously.

In Pro2, the distance of $\mathrm{O}-\mathrm{H}^{4}$ is shortened to $0.966 \AA$, denoting that the $\mathrm{H}^{4}$ atom has been transferred to the $\mathrm{O}$ atom and new $\mathrm{O}-\mathrm{H}^{4}$ bond is formed Both the $\mathrm{C}^{2}$ and $\mathrm{Ge}$ atoms adopt $s p^{2}$ hybridized state and the angle of $\mathrm{C}^{1} \mathrm{C}^{2} \mathrm{Ge}$ is $125.6^{\circ}$. The distance of $\mathrm{C}^{2}-\mathrm{Ge}$ is $1.789 \AA$, which is the normal $\mathrm{C}=\mathrm{Ge}$ double bond length.

A comparison between the two reaction pathways indicates that the two potential barriers along reaction (1) is 123.7 (Com $1 \rightarrow \mathrm{IM} 1$ ) and 58.5 $(\mathrm{IM} 1 \rightarrow$ Pro1) $\mathrm{kJ} / \mathrm{mol}$, respectively, which is quite lower than that along reaction (2) (reactants $\rightarrow \mathrm{IM} 2,171.0 ; \mathrm{IM} 2 \rightarrow \operatorname{Pro} 2,78.8 \mathrm{~kJ} / \mathrm{mol})$. Hence, it can be predicated that reaction (1) should be the leading reaction from the viewpoint of kinetic. At the same time, the reaction energy for the reaction (1) is -209.0 $\mathrm{kJ} / \mathrm{mol}$, which is lower than that of reaction (2) $(-82.9 \mathrm{~kJ} / \mathrm{mol})$. Therefore, from the thermodynamic viewpoint, Pro1 should be the dominant product.

\section{CONCLUSIONS}

In the present study, the mechanism of addition reaction between germylene and epoxyethane has been investigated at the B3LYP/6-311+G* level of theory. Geometry optimization, vibrational analysis, and relevant energy properties for the involved stationary points on the potential energy surface have been calculated. Two reactions (1) and (2) have been found. Reaction (1) is germylene attacks the $\mathrm{O}$ atom of epoxyethane to form a complex 1 (Com1), which is a barrier-free exothermic reaction. Com1 then isomerizes to IM1 via a transition state 1a (TS1a), where the potential barrier is 123.7 $\mathrm{kJ} / \mathrm{mol}$. Subsequently, IM1 can isomerize to a product Pro1 via TS1b with a potential barrier of $58.5 \mathrm{~kJ} / \mathrm{mol}$. The orbital interactions are also discussed to explain the combined process of leading complex. Reaction (2) is germylene attacks the $\mathrm{C}$ atom of epoxyethane firstly to form IM2 via TS2a, the potential barrier is $171.0 \mathrm{~kJ} / \mathrm{mol}$. Then IM2 isomerizes to a product Pro2 via TS2 b with a potential barrier of $78.8 \mathrm{~kJ} / \mathrm{mol}$. The reaction energy for the reaction (1) and (2) is -209.0 and $-82.9 \mathrm{~kJ} / \mathrm{mol}$, respectively. From the kinetic viewpoint, reaction (1) should be the leading reaction. At the same time, from the thermodynamic viewpoint, Pro1 should be the dominant product. Hopefully, the present results are expected to fill a void in the available data for the study of the interactions between germylene and the strained small-ring compounds.

\section{ACKNOWLEDGMENT}

This work is supported by the Scientific Research Foundation of Jinan University (XKY0709) and the foundation of Key Laboratory of Colloid and Interface Chemistry (Shandong University), Ministry of Education. We are highly grateful to the reviewer for his excellent suggestions to improve the presentation of the results.

\section{REFERENCES}

1. A. C. Filippou, J. G. Winter, G. kohn, J. Organomet. Chem. 544, 225, (1997).

2. A. C. Filippou, P. Portius, J. G. Winter, J. Organomet. Chem. 628, 11, (2001).

3. H. Ohgaki, W. Ando, J. Organomet. Chem. 521, 387, (1996).

4. U. Anandhi, R. Paul, Inorg. Chim. Acta. 359, 3521, (2006).

5. B. Pampuch, W. Saak, M. Weidenbruch, J. Organomet. Chem. 691, 3540, (2006).

6. S. Shoda, S. Iwata, K. Yajima, Tetrahedron. 53, 15281, (1997).

7. T. Iwamoto, H. Masuda, S. Ishida, J. Organomet. Chem. 689, 1337, (2004).

8. K. Olaf, L. Peter, H. Joachim, Polyhedron. 20, 2215, (2001).

9. B. Eric, M. Stephane, H. Nancy, G. Heinz, J. Organomet. Chem. 691, 5619, (2006).

10. C. Isobe, H. Cho, J. E. Sewell, Surf. Sci. 295, 117, (1993).

11. W. Du, L. A. Keeling, C. M. Greenlief, J. Vac. Sci. Technol. A 12, 2281, (1994).

12. C. G. Newman, J. Dzarnoski, M. A. Ring, Int. J. Chem. Kinet. 12, 661, (1980).

13. W. A. Hermann, R. S. Grev, H. F. Schdfer, Angew. Chem. 104, 1489, (1992).

14. N. Victor, I. Khrustalev, J. Organomet. Chem. 691, 1056, (2006).

15. T. Shinobu, T. Hiromasa, K. Eunsang, M. Shigeki, S. Kenkichi, J. Organomet. Chem. 691, 59, (2006).

16. R. Becerra, S. E. Boganov, M. P. Egorov, Chem. Phys. Lett. 260, 433, (1996).

17. B. Rosa, P. E. Mikhail, I. V. Krylova, Chem. Phys. Lett. 351, 47, (2000).

18. A. Ulan, D. K. Keith, D. L. Warren, Chem. Phys. Lett. 319, 529, (2000).

19. A. Ulan, A. T. Neil, D. K. Keith, D. L. Warren, Chem. Phys. Lett. 299, 291, (1999).

20. B. Rosa, W. Robin, J. Organomet. Chem. 636, 49, (2001).

21. Z. Y. Geng, Y. C. Wang, H. Q. Wang, Acta Phys. Chim. Sin. 20, 1417, (2004).

22. E. Broclawika, A. B. Janiszewska, J. Mole. Struc. (Theochem). 531, 241, (2000).

23. R. Fang, X. H. Zhang, Z. Y. Geng, J. Mole. Struc. (Theochem). 761, 53, (2006).

24. J. Satgi, Pure Appl. Chem. 56, 137, (1984).

25. B. Rivière, D. Monique, J. Organomet. Chem. 595, 153, (2000).

26. N. Tokitoh, K. Kishikawa, R. Okazaki, Polyhedron. 21, 563, (2002).

27. P.Hohenberg, W. Kohn, Phys. Rev. B 136, 864, (1964).

28. A.D. Becke, J. Chem. Phys. 98, 5648, (1993).

29. C. Lee, W. Yang, R.G. Parr, Phys. Rev. B 37, 785, (1988).

30. K. Fukui, Acc. Chem. Res. 14, 363, (1981).

31. C. González; H. B. Schlegel, J. Phys. Chem. 94, 5523, (1990).

32. A. E. Reed; L. A. Curtiss; F. Weinhold, Chem. Rev. 88, 899, (1988).

33. M. J. Frisch et al., Gaussian 98 (Gaussian Inc., Pittsburgh, PA, 1998). 